a designação de "grés de Moura», no complexo miocénico continental por G. Znyszewsit, M. Feio e F. Moitinho de Almeida $\left(^{2}\right)$. Segundo estes autores, os «grés de Moura» são constituídos por «grés com cimento argiloso ou calcário», semelhantes aos «grés sahelianos» da bacia do Sado, pelo que os consideram como equivalentes laterais. Ainda segundo os mesmos autores, os níveis mais altos do depósito detritico de Moura «apresentam-se fortemente impregnados de calcário, originando uma

\section{NOTA SOBRE OS DEPÓSITOS TERCIÁRIOS DE MOURA}

O estudo pormenorizado dos depósitos de cobertura do Alentejo, indispensável para a compreensão da morfologia desta vasta área, é uma das realizações em curso no Laboratório de Geomorfologia do Centro de Estudos Geográficos de Lisboa.

$\mathrm{Na}$ presente nota prévia descrevem-se os primeiros resultados obtidos pelo estudo da amostragem relativa a dois cortes efectuados nos arredores de Moura. Um deles, dirigido de Moura para os Moinhos da Barca, no vale da ribeira de Torjais, até o contacto com os micaxistos do soco, o outro, de Moura até a ribeira da Amoreira, na estrada de Brinches, onde se vêem os depósitos assentes sobre o granito (granito de Pias).

Os depósitos terciários de Moura fazem parte de extensa cobertura sedimentar, discordante sobre o soco, de que restam alguns testemunhos, maiores ou mencres, dispersos por vasta área ligada à actual bacia do Guadiana. Com efeito, desde Campo Maior e Elvas, a norte, passando por Juromenha, Reguengos, Monte do Trigo, Mourão, Amareleja, até Cuba, Vidigueira e Moura, a sul, são frequentes os retalhos da citada cobertura. Depósitos idênticos, pertencentes ao mesmo conjunto, existem para lá da fronteira luso-espanhola (fig. 1).

Os depósitos de Moura foram objecto de breve referência por parte de P. BIRot e M. FEIo (1), que os referem uniforme e globalmente como calcários lacustres, e para os quais admitem idade oligocénica, sem contudo o afirmarem. As mesmas formações foram incluídas, sob

(50) JeAn LABASSE, L'organisation de lespace. Éléments de Géographie volontaire. Hermann, aris, $1966,605 \mathrm{pp}$

(') P. Birot e M. FEIO, "Notes sur la morphologie du Portugal méridional", Mélanges Géographiques offerts en hommage ḋ Daniel Faucher, pp. 103-127, Toulouse, 1948.

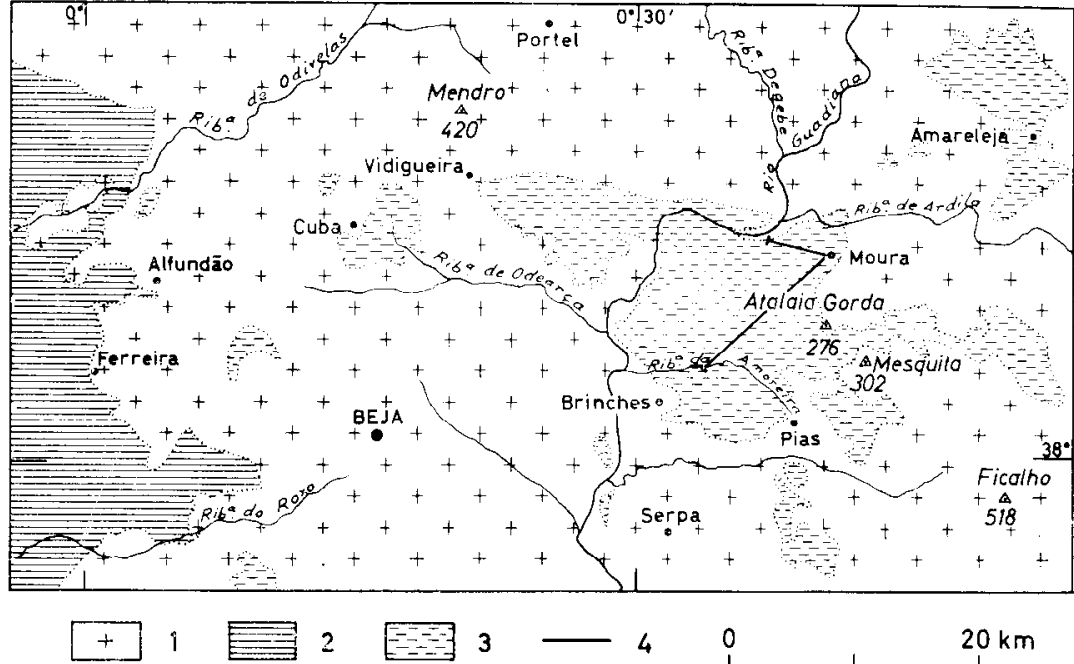

Fig. 1 - Enquadramento geológico da regiâo de Moura

1-Maciço antigo; 2 -bacia terciária do Sado; 3 -depósitos

da bacia do Guadiana; 4-localização dos cortes estudados.

rocha dura que faz passagem a calcários gresosos». Esta parte superior consideram-na contemporânea dos calcários pontianos do Ribatejo. No mesmo trabalho cita-se, ainda, o aparecimento de restos indetermináveis de ossos de mamiferos, entre os quais um que faz lembrar Pseudaelurus, provenientes de um local perto da Quinta dos Pisões.

Em 1951, M. FEIO (") torna a referir-se a estes depósitos, sem modificar a posição que tomara anteriormente, de colaboração com G. Zisszewshi e F. Moitinho de Almeida (1950, op. cit.).

Os estudos de laboratório a que procedemos com o material dos cortes efectuados permitem supor a existência de dois complexos sedi-

() G. Zвyszewski, M. Frio e F. Moirinho de Almeida, «Contribuição para o conheciCientejon, Comunicação apresentada ao XIIT Congrosa - Espankol para o Progresso das Ciências, tomo v, 4.a Seç̧ão, pp. 509-530, Lisłoa, 1950

(3) M. Fвı, "A evolução do relevo do Baixo Alentejo e Algarve", Comanicaçóes dos Serviços Genlógicos de Portugal, tomo xxxi1, 2.a parte, pp. 303-477, Lisboa, 1951. 
mentares, caracterizados em especial pela natureza das respectivas fracções argilosas:

II - Complexo Superior -- essencialmente montmorilonítico.

I - Complexo Inferior - essencialmente atapulgítico.

Em seguida apresentam-se, de forma abreviada, os resultados do estudo sedimentológico dos materiais constituintes dos vários níveis litológicos que compõem o conjunto. Estes resultados permitem, como se verá, esboçar algumas hipóteses quanto à estratigrafia dos depósitos e evolução paleogeográfica correlativa.

\section{I - COMPLEXO INFERIOR}

1 - Calcários compactos, levemente areniticos e pouco argilosos $\left({ }^{4}\right)$, constituem o mais baixo nível deste complexo. Äs vezes, estas rochas encontram-se mais ou menos silicificadas e apresentam frequentes impregnações dendríticas, manganesíferas. A fracção detrítica, embora escassa, está representada por grãos de quartzo subangulosos e sub-rolados, algo, mas pouco, brilhantes. O calcário do monte do Ameixial contém, além destes tipos, grãos rolados brilhantes. Há, evidentemente, grande percentagem de detritos angulosos, característicos das fracções mais finas (em geral, as inferiores a $0,25 \mathrm{~mm}$ ). Refere-se, ainda, a presença de grãos com corrosão superficial. Na fracção arenosa, além de elementos quártzicos, existe feldspato vestigial, e, como elementos líticos, apenas está representado quartzito.

As observações relativas à natureza dos minerais pesados, identificados nas várias amostras, resumem-se do seguinte modo: ao passo que a turmalina, como é natural, é muito abundante nos sedimentos sobrepostos ao granito, a granada ocupa posição de relevo nos do monte do Alvarrão (assentes sobre os calcários metamórficos). Apenas se observou presença significativa de andaluzite nos calcários do monte do Ameixial (sobre os micaxistos), embora figure noutras amostras, em menores percentagens. A distribuição do epídoto é muito mais uniforme, pois é comum em todos os sedimentos analisados. Este mineral existe em várias rochas constituintes do substrato da região, tais como micaxistos, rochas verdes, leptinitos e corneanas cálcicas.

Há, naturalmente, para cada local, forte contribuição das formações antigas, imediatamente subjacentes, e contaminação evidente de outras mais afastadas.

(4) Localização do material estudado:

501-10 - Estrada de Moura a Moinhos da Barca, junto ao monte do Ameixial (sobre micaxistos); a $130 \mathrm{~m}$ de altitude.

511-4 - V. G. de Covas (a sul das minas da Orada); a $140 \mathrm{~m}$ de altitude.

$512-2-500 \mathrm{~m}$ a NW do monte da Figueira (Machados). Aqui o substrato é constituido pelo granito de Pias profundamente arenizado; a $140 \mathrm{~m}$ de altitude.

512-5 - Monte do Alvarrão (sobre calcários metamórficos); a $140 \mathrm{~m}$ de altitude.

$512-7-3 \mathrm{~km}$ a SW de Moura, na estrada para Brinclies; a $180 \mathrm{~m}$ de altitude.
A natureza da fracção argilosa nestes calcários tem como característica comum a presença de atapulgite. Associam-se-lhe outras argilas, como ilite e montmorilonite. Nos níveis mais altos desta primeira unidade estratigráfica o teor de montmorilonite parece aumentar.

2 - Arenitos de cimento calcário, compactos, com calhaus sub-rolados (i). Fazem parte do complexo inferior; foram observados, apenas, no corte de Moura a Moinhos da Barca, sobrepostos aos calcários da base.

Os calhaus rolados parecem constituir intercalações conglomeráticas no seio dos arenitos. Entre estes elementos detríticos grosseiros, sub-rolados e mais ou menos achatados, encontram-se calhaus de quartzo filoniano, de quartzito, de lidito e de outras rochas xistóides, mais ou menos silicificadas.

Granulomètricamente, a fracção arenosa tem distribuiçāo simétrica $($ Skqø $=0)$ e pouco dispersa ( $Q d ø=0,65)$ (fig. 2). Estas características associadas ao tipo morfoscópico dos grãos de quartzo - sub-rolados pouco brilhantes e brilhantes (SR-PB e SR-B) e rolados brilhantes $(R-B)-$ permitem correlacionar esta camada com episódio fluvial que abarranca a série inferior.

A fraç̧ão arenosa apre-

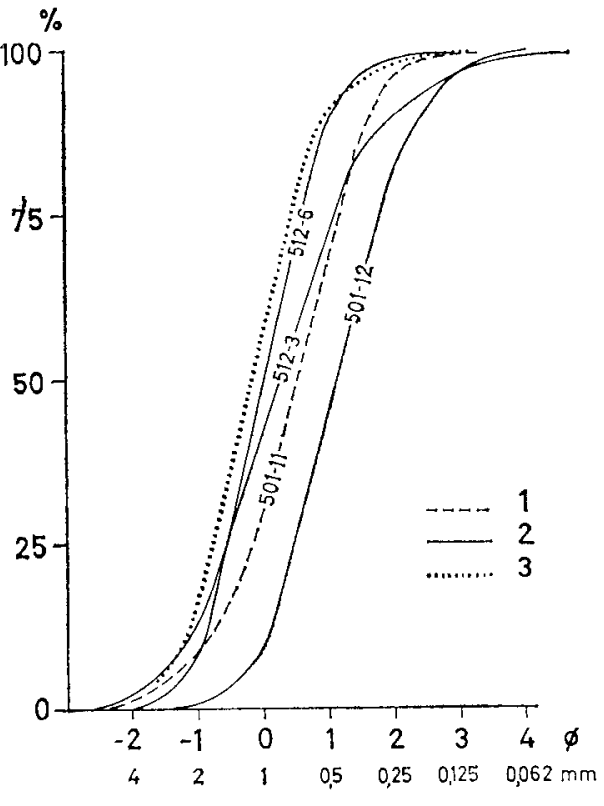

Fig. 2-Curvas granulométricas acumulativas da fracção arenosa dos depósitos terciários de Moura - complexos inferior (1) e supeperior (2) - e de uma areia do

leito actual do Guadiana (3). senta feldspato, em pequena percentagem ( 2 a 5 p. 100), e elementos liticos, tais como xisto metamórfico (5 a 10 p. 100) e raro lidito. No que respeita aos minerais pesados, verifica-se a presença de turmalina e andaluzite (abundantes) e granada e epídoto, em menore quantidades. Há, pois, mistura de cortejos mineralógicos próprios dos diferentes tipos petrográficos que constituem o substrato das regiões vizinhas.

Quanto à composição argilosa dos arenitos, há predomínio de montmorilonite, acompanhada de atapulgite, ilite e caulinite.

(5) 501-11 - Estrada de Moura a Moinhos da Barca, junto ao monte do Ameixial, a $130 \mathrm{~m}$ de altitude. A composição fundamental desta rocha, expressa em fraçōes
arenosa, argilosa e carbonatada, é de $60 \%, 2 \%$ e $38 \%$, respectivamente. 
Somos levados a pensar, à semelhança do que se verifica noutros pontos da bacia do Tejo, que o complexo inferior, essencialmente atapulgítico, se torna, para o topo, progressivamente mais rico de montmorilonite. De facto, o calcário sobre que assenta apresenta, já, certa percentagem desta argila. Também o calcário colhido três quilómetros a SW de Moura (na estrada para Brinches), situado a maior altitude, parece indicar este tipo de substituição.

\section{$\mathrm{II}$ - COMPLEXO SUPERIOR}

1 - Arenito de grão mais ou menos fino, de cimento margoso ("). Estas formações assentam directamente sobre os calcários do complexo inferior e observam-se por toda a área. Apenas no corte de Moura a Moinhos da Barca se observa excepção a esta regra. Existe ali, como se referiu, um arenito conglomerático fazendo como que transição entre os dois complexos. Entre eles deve existir lacuna de erosão cuja amplitude não é possivel avaliar com rigor. Os arenitos do complexo superior são coroados por extensa camada de calcário, apenas interrompida pela incisão da rede fluvial. Apresentam colorações variáveis (esverdeada, esbranquiçada, amarelada e acastanhada clara). Contêm intercalações argilo-margosas e níveis conglomeráticos dispersos, que parecem predominar no topo deste nivel, sobretudo no bordo norte do grande afloramento terciário de Moura. Nestas cascalheiras são frequentes as colorações avermelhadas.

Apenas este nível (II, 1), sem dúvida o melhor representado na região estudada, possui as características atribuídas aos chamados «grés de Moura», pelos autores referidos atrás.

As análises granulométricas efectuadas revelam curvas muito semelhantes (fig. 2) de que se deduziram valores de $Q$ dø compreendidos entre 0,4 e 0,8 e de Skqø nulcs. Estes números indicam boa calibragem de sedimentos obtida no decurso de transporte fluvial.

Os grãos de quartzo são dos tipos SR-PB e R-B, facto que confirma a origem fluvial destes sedimentos.

Além de quartzo, os arenitos deste nível possuem feldspato, em muito pequena percentagem (não excede 5 p. 100), e raros grãos de xisto metamórfico.

O cortejo de minerais pesados mantém-se mais ou menos constante ao longo do referido nivel. Por ordem decrescente de frequência cita-se a presença de andaluzite, epídoto, turmalina, granada, silimanite e zircāo.

(9) Localizaçâo do material estudado:

501-12 - Estrada de Moura a Moinhos da Barca, junto co monte do Ameixial; a $130 \mathrm{~m}$ de altitude.

501-13 - Idem, $500 \mathrm{~m}$ a NE do monte do Ameixial.

$512-3-1 \mathrm{~km}$ a E do V. G. de Mantana, na estrada para Brinches; a $170 \mathrm{~m}$ de altitude. $512-4$ - Idem.

$512-6-3 \mathrm{~km}$ a SW de Moura, na estrada para Brinches; a $180 \mathrm{~m}$ de altitude.

512-8 - $1 \mathrm{~km}$ a $\mathrm{S}$ do monte da Merendeira, na estrada para Brinches; a $160 \mathrm{~m}$ de altitude. A média dos valores encontrados fornece a seguinte composişño:

Fraç̧ão arenosa-90 $90 \%$; fraç̧ão argilosa $-5 \%$; fraç̧̃̃o carbonatada $-5 \%$.
Esta associação indica multiplicidade de fontes de alimentação, à semelhança do que foi referido a propósito do complexo inferior.

Muitos destes minerais apresentam-se em grãos bem rolados (zircão, granada, turmalina e andaluzite). Se, por um lado, este facto confirma o regime fluvial e a origem mais ou menos longínqua dos materiais, não deixa de suscitar a hipótese da coexistência de materiais rolados, oriundos de sedimentos préexistentes, retomados em novo ciclo. De facto, a grande dureza e a resistência à meteorização, que os caracterizam, permitem tal conjectura.

Os elementos detríticos grosseiros das lentículas conglomeráticas, intercaladas, são constituídos essencialmente por calhaus de quartzo filoniano subangulosos a sub-rolados $(2 \mathrm{r} 1 / \mathrm{L}$ compreendido entre 0,04 e 0,07 ), de pequenas dimensões (comprimento não superior a $5 \mathrm{~cm}$ ).

O deficiente grau de rolamento destes calhaus não parece compatível com a presença de areias roladas a que estão associados. E lógico admitir a existência de relevos residuais (à semelhança, por exemplo, dos que ainda hoje formam os cabeços de Atalaia Gorda e de Mesquita), susceptiveis de fornecer, localmente, materiais muito menos trabalhados pelo transporte.

A predominância dos níveis de materiais grosseiros (situados no topo dos arenitos de Moura) no bordo norte do grande afloramento terciário da regiāo poderá indicar estreita relação com o acidente tectónico posto em evidência pela actual escarpa da Vidigueira.

A composição argilosa dos sedimentos incluídos nesta rubrica é constituída por montmorilonite, predominante, e, acessòriamente, ilite e caulinite.

A fracção carbonatada, quando existe, pode corresponder a fenómenos de impregnação, a partir do horizonte calcário que se lhe sobrepõe.

2 -.-Calcários brancos, pouco areniticos, mais ou menos compactos (calcários de Moura) ('). Este nivel, o mais elevado dos quatro considerados nos depósitos terciários visíveis e estudados na região, assenta em concordância sobre os arenitos referidos atrás. Corresponde a extensos retalhos planálticos, num dos quajs está situada a vila de Moura.

Estes calcários, muito semelhantes acs calcários lacustres miocénicos da bacia do Tejo, são mais ou menos compactos; podem apresentar-se porosos e pulverulentos, com falso aspecto de margas.

Os raros detritos, em geral finos, inclusos na massa do calcário, são formados por grãos de quartzo, sub-rolados e rolados, mais ou menos brilhantes, por outros com corrosão superficial e por algum feldspato. Os minerais pesados são, pràticamente, os mesmos referidos nos arenitos do nivel anterior. A fracção argilosa é essencialmente constituída por montmorilonite, como nos arenitos subjacentes.

(i) $512-9-4 \mathrm{~km}$ a SW de Moura, na estrada para Brinches; a $190 \mathrm{~m}$ de altitude. A composição fundamental é a seguinte Fraç̧ão arenosa-3\%; fraç̧ão argilosa $-5 \%$; fraç̧ão carbonatada - $92 \%$. 
Em conclusão, diremos que existem na região dois ccmplexos, um inferior, atapulgítico, e outro superior, montmorilonítico (fig. 3). Cada um pressupõe condições morfoclimáticas distintas.

o complexo inferior começa por um horizonte calcário, rico de atapulgite e de impregnações de sílica. Tais características correspondem às condições de sedimentação essencialmente química básica. Junto ao monte do Ameixial, este complexo termina, na parte superior, por um nivel arenítico, com calhaus cujas características denunciam a exis-

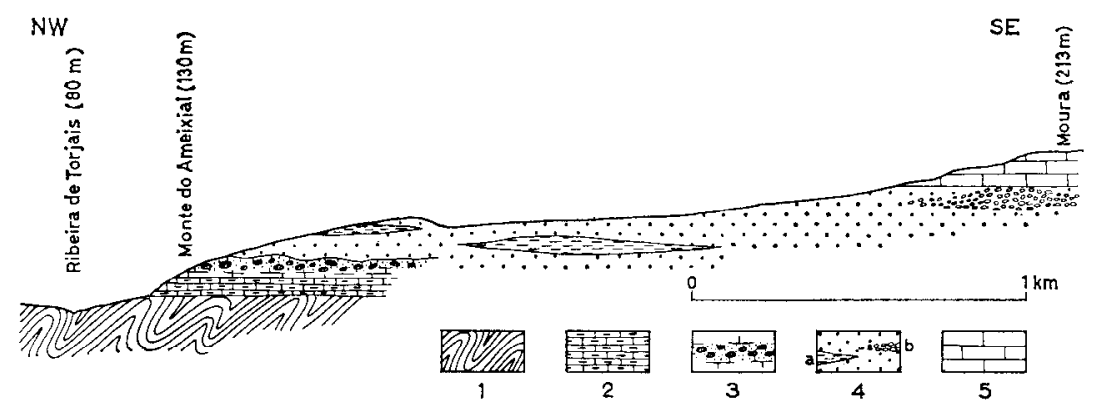

Fig. 3 - Corte geológico, esquemático, da região compreendida entre Moura e a ribeira de Torjais.

1 - Micaxistos; 2 -- calcários compactos com atapulgite;

3 - arenitos com calhaus sub-rolados; 4 -arenitos de

Moura, com intercalaçōes argilo-margosas (a) e níveis conglomeráticos (b); 5- calcários de Moura.

tência de episódios fluviais; este parece abarrancar a série inferior, de aspecto lacustre.

A semelhança de outras regiões do país, este complexo deve corresponder ao Paleogénico, não sendo de excluir a hipótese de sc considerar, em parte, como Eocénico $\left({ }^{8}\right)$.

A ausência de formações grosseiras, significativas, na base dos depósitos terciários de Moura, parece indicar esta região como tendo ocupado posição mais ou menos central em relação à bacia de sedi mentação, portanto, afastada dos bordos da mesma, onde havia condições para sedimentarem tais formações detriticas.

Esta hipótese é sugerida pelo conhecimento que temos acerca do carácter grosseiro dos mais baixos depósitos paleogénicos, marginais da bacia do Tejo $\left({ }^{\circ}\right)$. É provável que no sopé de alguns relevos residuais de então, como Atalaia Gorda e Mesquita, já referidos, o nível equivalente lateral dos calcários do monte do Ameixial se apresente rico de detritos, facto que só poderá ser confirmado por sondagens; a topografia local não permite a sua obser̀vação directa.

(8) A. M. Galopim de Carvalho - "Atapulgite em alguns depósitos sedimentares portugueses. Considerações estratigráficas e morfoclimáticas». Finisterra, vol. 11-4, pp. 174-200, 1967.

(9) Idem-Contribuição para o conhecimento geológico da bacia do Tejo. Memórias dos Serviços Geológicos de Portugal, nova série, n.0 15, Lisboa, 1968. $210 \mathrm{pp}$.
A zona em causa situava-se no interior de extensa área deprimida tectònicamente em relação à superfície pré-paleogénica, e formava, portanto, o centro de convergência da drenagem das regiões circundantes. Não longe desta área, na região de Marmelar, aos calcários atapulgíticos da base, equivalentes destes, sobrepõe-se um depósito detrítico grosseiro de aspecto torrencial, também atapulgitico (Complexo de Marmelar), que atinge junto à escarpa de falha da Vidigueira a espessura de $10 \mathrm{~m}$ a $20 \mathrm{~m}$. Esta formaçāo é correlativa do primeiro rejogo desta importante falha, ocorrido nos tempos cenoantropozóicos (10).

O ambiente climático, talvez de tipo quente e húmido, era propício a intensa actividade de meteorizacão; a sedimentação, nestas condições morfoclimáticas, só poderia ser, portanto, de tipo químico de carácter básico.

O complexo superior de Moura comeca por extensa camada de arenitos, em geral de grão fino, cuja espessura atinge $30 \mathrm{~m}$ a $40 \mathrm{~m}$. As características sedimentológicas deste depósito permitem supor ambiente morfoclimático diferente do admitido para o complexo inferior. $\hat{E}$, pois, muito provável a existência de lacuna entre os dois.

Em primeiro lugar, a natureza essencialmente detritica dos depósitos, de aspecto fluvial, permite encarar a região, não como centro de drenagem centripeta, mas como zona de passagem, onde os materiais se acumulavam, por vagas sucessivas, no decurso do transporte em vasta planície aluvial (11).

As intercalações de materiais grosseiros, especialmente desenvolvidas no topo dos arenitos de Moura, sobretudo no bordo norte da grande mancha terciária, sugerem correlação com a falha da Vidigueira. O depósito poderá, assim, explicar-se por novo rejuvenescimento do dito acidente em periodo anterior ao calcário lacustre (Pontiano?) e mais ou menos contemporâneo dos niveis mais altos dos arenitos de Moura.

O carácter torrencial destas formações assemelha-as a outras existentes na regiāo de Marmelar, embora pertençam a níveis diferentes: às cascalheiras do complexo de Marmelar, já referidas, e às do complexo de Mesas (essencialmente ilito-caulinítico), Vilafranquiano. Também estas últimas se encontram correlacionadas com possivel rejogo da falha da Vidigueira, ocorrido nos últimos tempos do Terciário ou início do Quaternário (M. FeIo, 1951, op. cit., e C. DE OLIVEIRA ALvEs, 1969, op. cit.).

Nestes níveis detríticos grosseiros acumulam-se calhaus mal rolados (provàvelmente carreados também de relevos residuais vizinhos) com areias bem roladas, certamente oriundas de regiões mais longinquas. Algumas destas intercalaçõcs poderão corresponder a eixos de drenagem divagante, em períodos de maior competência.

(10) C. De Oliveira Alves - A região de Marmelar. Contribuiçãa para o seu estudo geomorfológico e sedimentológico. Dissertaçāo de licenciatura em Geografia, apresentada à Facul dade de Letras de Lisboa. Lisboa, 1969, 100 pp. policopiadas.

(11) A título de comparaşão fez-se a granulometria da areia do leito do Guadiana em tos (fig. 2) 
Em oposição a tais episódios grosseiros, as lentículas argilo-siltosas podem corresponder a deposição calma por decantação de materiais finos em áreas alagadiças, como meandros abandonados.

A espessura considerável da série arenítica indica que se mantiveram constantes as condições dinâmicas da depcsição. Tal constância pode ser imaginada como consequência de um processo de subsidência ou de variação positiva do nível de base. Atendendo a que a transgressão vindoboniana atingiu, na bacia do Sado, as regiões de Alfundão e Ferreira do Alentejo, formando aí extenso golfo, é fácil imaginar a zona de Moura situada na parte vestibular do sistema hidrográfico responsável pela sedimentação aluvial ali existente. Não se pretende excluir a hipótese de subsidência da área considerada. $\overline{\mathrm{E}}$ provável, até, que se tenham verificado ambas.

O ambiente climático correlativo destes arenitos é dificil de imaginar à falta de argumentos suficientemente abundantes e seguros.

O recurso à composição mineralógica das areias é dificultado pelo facto de se não poder afirmar se a pobreza de feldspatos é devida à ausência de afloramentos graníticos, ou, existindo, muito arrasados, ou se é consequência de meteorização intensa. Um transporte suficientemente prolcngado podia ter produzido, também, idêntico resultado.

O elemento mais significativo é dado pela composição argilosa que parece indicar a existência de condições propícias à arenização, isto é, de tipo temperado, em geral. Admite-se assim por se não poder atingir maior precisão.

Se existir a lacuna referida na passagem de um complexo ao outro, com base no que se conhece noutras regiões do país e nas correlações alvitradas por G. ZBYSzewski, M. Feio e F. MOITINho DE ALMEIDA (1950, op. cit.), os arenitos de Moura podem, de facto, ser equivalentes laterais das formações miocénicas continentais das bacias do Sado e do Tejo. A lacuna aludida representaria lapso de tempo de difícil enquadramento, quer no que se refere ao limite inferior, visto que a idade do complexo atapulgítico, paleogénico, não pode ser definida com rigor (Eocénico? e/ou Oligocénico?), quer relativamente ao limite superior que, como se viu, também não permite maior precisão (Miocénico?).

Os calcários de Moura correspondem, no geral, a sedimentação pcr precipitação química, em ambiente de águas relativamente paradas, mais de tipo pantanoso do que lacustre. Os raros elementos detríticos existentes nos ditos calcários mostram ter havido acarreios detríticos, embora pouco significativos.

A continuação da subsidência da região ou da transgressão, aludidas atrás, poderiam explicar as condições de estagnação propícias à sedimentação calcária. Do regime de deposição detrítica expresso pelos arenitos de Moura passa-se a outro em que predomina a precipitação carbonatada. Nestes termos, não parece necessário encarar modificação climática apreciável, tanto mais que os argumentos são insuficientes.
Quanto à idade deste último nível, as nossas observações conciliam-se com a hipótese emitida por G. Zisyszewski, M. Feio e F. Mortinho DE Almeida (1950, op. cit.) que o consideram como equivalente dos calcários pontianos do Ribatejo.
A. M. GALOPIM DE CARVALHO

E C. DE Oliveira Alves 